\title{
The Sustainability of Malaysia's Defined Contribution Pension System: Implementation of Deterministic Linear Programming
}

\author{
RoslanJa'afar, Kevin James Daly
}

\begin{abstract}
This article investigates, under deterministic linear programming model, asset allocation decision and optimal investment strategy for Malaysia's defined contribution pension (DC) scheme -Employees Provident Fund (EPF). The model requires generation of scenarios and probabilities to represent future assets and liabilities streams. We employed Vector Autoregressive (VAR) model to generate future returns of five asset classes i.e. equity, money market instrument, Malaysia government bond with 1 and 10 years of maturity date and property. Future liabilities factors were derived from two submodels; population and salary. In population model, the future status of the EPF members was determined using a Markov Chain model. Then, the random factors of assets and liabilities were used in the asset liability model (ALM) based on linear programming $(L P)$ and fixed mix (FM) strategy. The results of the research are grouped in two levels. First, we briefly discuss the finding of the random factor model and then we analyse the optimal investment strategy for the EPF. In terms of finding an optimal investment strategy, the FM strategy generated higher expected terminal wealth than the LP strategy. This finding suggests that FM strategy is superior to the LP strategy. In addition, we find that the higher dividend distributed to the members may result in decreasing of the expected terminal wealth of the fund for both strategies. This portrays that dividend distribution policy may affect the financial soundness of the EPF in the long run.
\end{abstract}

Keywords: Linear programming, optimal asset choice, the $E P F, A L M$

\section{INTRODUCTION}

Population ageing and uncertainty surrounding investment returns, affects pension fund providers and governments in developing a sustainable pension system. Asset allocation decision and optimal investment strategy are becoming increasingly important to ensure that the fund is always adequate and sustainable to meet its liabilities as well as satisfying regulatory requirements. Market uncertainty and regulatory constraints require the fund to use alternative investment strategy to construct its asset allocation efficiently.

In any year funds experiencing decreasing mortality rates of members along with declines in fertility rates cause pension schemes to become imbalanced where funds to beneficiaries exceed contributions to the system [2]. [13]showed that investment policy significantly influenced the performance of a pension system. We define strategic investment strategy as a decision to allocate portfolios across broad asset classes including bonds, equity, real

Revised Manuscript Received on September 14, 2019.

RoslanJa'afar, UKM-Graduate School of Business, the National University Malaysia, Malaysia, School of Business, Western Sydney University, Australia. (E-mail: jroslan@ukm.edu.my)

Kevin James Daly, School of Business, Western Sydney University, Australia estate and cash as well as considering varying limitations on allocations as directed by the funds management. Previous studies suggested that $90 \%$ of investment performance was explained by asset allocation while active investment management only contributed $10 \%$ [1]

In this respect, we address the issue of optimal investment strategy for Malaysian pension system with the presence of uncertainties and constraints. To develop an optimal strategy within the context of a pension fund, the management of asset and liabilities must be performed in a simultaneously environment [10]. On the complexity of managing pension funds, which requires the fund to meet its liability requirements as well as satisfy the regulatory framework, we present asset liability management (ALM) based on a deterministic linear programming model

Using an asset liability management model, this paper explores the investment decision making strategies of the Malaysia Employees Provident Fund (the EPF). The motivation behind this study is to assist the EPF in deciding how available funds should be allocated across the financial markets in order to provide an optimal return which is able to cover future liabilities and provide a high return for the EPF's members. Thus, in this study, we used the stochastic model to assign uncertain asset and liabilities stream which is applied in deterministic linear programming. Next, using the same input generating from stochastic modelling, we analyse the optimal allocation based on fixed mix strategy where, the portion of the asset allocation is predetermined and fixed at the beginning of the investment planning. Then, the results for both LP and fixed mix model are compared.

This paper contributes to the existing literature due to three innovations. Firstly, the study on Malaysia pension system using stochastic are very rare and only [6] in her thesis employed a similar investment strategy. Thus, this paper is aiming to fill the gap in the literature specifically stochastic modelling for developing countries like Malaysia. The second contribution of this study is that the model used in this paper is tailored to the Malaysia case. In light of this, the model has a uniqueness factor in terms of Malaysian perspective. In addition, from a practitioners' perspective, this study contributes to the fund managers understanding regarding the derivation and development of current active members as well as the projection of future cash flow using an appropriate stochastic model. One key issue for the fund is to develop a pension system soundness by depending on the benefits to be paid as well as on the correct projections for contribution from future active members. 


\section{THE SUSTAINABILITY OF MALAYSIA'S DEFINED CONTRIBUTION PENSION SYSTEM: IMPLEMENTATION OF DETERMINISTIC LINEAR PROGRAMMING}

This article is structured as follows: in the next section, we briefly discuss the practise of the EPF in the context of investment strategy and performance. In the section four, the ALM is employed using deterministic linear programming (LP) model and finally we present the results along with some concluding comments in the final section of the paper.

\section{METHODOLOGY \&MALAYSIA'S EPF AND ISSUES}

The EPF was established by the British colony is an employee provident fund which primarily focuses on formal private employees. This system was established in 1952 under the EPF ACT 1952 and it is based on defined contribution (DC) scheme where the employee and employer are required to pay a pre-determined percentage of contribution from employee's salary into an individual retirement account. Then this contribution is managed by the EPF by investing it in financial market, which may generate returns with more secure manner. The final benefit of this plan is unknown and subject to contribution and return of investment. Therefore, the investment strategy is essential for this plan at the same time it is a vital factor used to increase public confidence towards the institution and the pension plan in providing adequate pension saving.

To protect members' savings, the EPF Act 1995, makes it compulsory for the EPF to contribute at least $2.5 \%$ as a dividend to its members annually. The EPF's 2014 annual report indicates that the EPF has never failed to pay dividends above $4 \%$ since its inception. Although the EPF does provide good dividends to their members (i.e. above compulsory rate), it still does not guarantee members to retire on a decent pension allowing members at least to maintain an adequate standard of living after retirement. According to [7], employing data from the 2014 EPF annual report, a member who retires at the age of 56 typically receives a lump sum of RM180,152 on average. Such a retirement pension means that for someone living until 75 years old receives an average monthly income of less than RM750.63 per month which is slightly below the poverty line.

The fact above depicts a situation where the EPF is failing to provide an adequate pension saving for its members. the results are also supported by a survey conducted by [12], who studied the financial positions of the elderly across 3 major cities in Malaysia, Singapore and the Philippines. Their finding shows that $66.8 \%$ believed that the EPF accumulated fund is inadequate for their retirement consumption. Thus, in this study, we aim to derive the performance of the pension fund for Malaysia by deriving an optimal investment strategy that may increase the investment return.

\section{THE DECISION MODEL}

Similar to other pension systems, the EPF is responsible for collecting premium (contribution) from both employers and employees at a fixed statutory contribution rate, to pay pension benefits toward retirement and to invest available wealth in the financial markets. In addition to these ordinary functions, the EPF allows members to withdraw a certain amount from their account before reaching retirement age.
However, they are only allowed to withdraw its EPF fund for selected categories such as for medical treatment, purchase or construction of house, education as well as performing hajj. Thus, in modelling liability factors, both claims must be taken into account.

The EPF manages the remaining wealth by investing it in the financial market and in this study the EPF will invest the assets, $\mathrm{i}$, in the five broad asset classes- government bond, loan and bond, equity, property and in money market instrument with 45 years' investment planning horizon (T). We used 2015 data as the based year for this analysis. The deterministic LP model indices are as follows:

$$
\begin{array}{ll}
\text { Asset classes } & i=1, \ldots, I(I=5) \\
\text { Time } & t=1, \ldots, T(T=45)
\end{array}
$$

The decision of buying, borrowing and lending are made at the beginning of the period. The aim of the investment strategy is to maximize the expected terminal value of the fund. Asset returns and liability factor are based on stochastic programming and then we replace the random parameters with the expected value to be used in the deterministic model. We then extend the analysis by testing the model with fixed model analysis. At the end, we compare the performance for both LP and FM model in the optimization investment strategies. In modelling the deterministic ALM model, we begin modelling by explaining the basic ALM model, the objectives function and constrains stemming from the EPF policies. LP is a mathematical program where the objective function and the constraints functions are all linear [15]. From a mathematic perspective, this process is represented using matrix notation as:

$$
\begin{aligned}
& \min _{x} \mathrm{f}(\mathrm{x}) \\
& \text { subject to } \\
& \qquad \underset{\mathrm{x}}{\mathrm{g}(x)=0, \mathrm{i}=1, \ldots, \mathrm{n}} \\
& \\
& h j(\mathrm{x}) \leq 0, \underset{x}{\mathrm{j}}=1, \ldots, \mathrm{m}
\end{aligned}
$$

where $x, f(x)$ are referred to as decision variable(s) and the objective function and $\mathrm{g}(\mathrm{x}), \mathrm{h}(\mathrm{x})$ are constraints. This model is referred as linear optimization model since the objective function and all constraints are mentioned in linear form.

\subsection{Objective function}

The objective function for a dynamic asset allocation strategy normally refers to the goal of the fund such as maximizing terminal wealth at the end of the planning horizon as well as minimizing a stochastic contribution rate. In the case of the EPF, we consider the objective function for our model is to maximize terminal wealth of the fund so that can provide higher returns and dividend to the members. The objective the EPF's fund manager is expressed as follows;

$\operatorname{Max} E(W t)$

The objective for this model reflects the goal of the fund to reach the largest possible gains at the end of investment decision horizon with the presence of risk, regulatory and liability constraints. 


\subsection{Decision constraints}

One of the constraint that need to be taken into account by the fund is the presence of legal and policy constraint in deriving the decision process. The objective of this constraints is to control or to minimize the risk of losses which adversely affect the future pensioners [13].

\subsubsection{Asset management}

An asset management model for ALM describes the dynamic of holding cash in the asset class. This constraint shows the portfolio composition over the time. The model is described as the following equation:

$$
\begin{aligned}
& H_{i, 0}=H_{i, 0}+B_{i, 0}-S_{i, 0} \\
& H_{i, t}=H_{i, t-1}\left(1+r_{i t}\right)+B_{i, t}-S_{i, t}
\end{aligned}
$$$$
i \in A ; t=1, \ldots, T-1
$$

where $H_{i, 1}$ is an initial holding allocated to each asset, $H_{i, t}$ amount of assets $i$ held at time t scenarios $s, r_{i, t}$ return on asset $i$ over period $t, B_{i, t}$ decision of buy asset $i$ at time $t$ (nonnegative value) and $S_{i, t}$ represents decision to sell asset $i$ at time $t$ (nonnegative value).

Asset management suggest that the portfolio is readjusted at the discrete time during the planning horizon which will involve buying and selling assets decision. Inventories at time 1 is represented by the initial holding (actual data from year 2014 as reported by the EPF's annual report) plus amount of assets bought minus amount of assets sold as in equation (3). While in equation (4), amount of assets held at time $t$ are equal to the amount hold at the previous time and its return plus the amount bought and the amount sold.

\subsubsection{Budget constraint}

The next constraint under ALM model is a budget constraint. This constraint displays cash inflows and cash outflows along the investment horizon. At the $\mathrm{t}=0$, we describe budget constraints as follows:

$$
\sum_{i=1}^{I}(1+\alpha) B_{i, 1}^{S}+Q_{1}^{S}+L_{1}=C_{1}+\sum_{i=1}^{I}(1-\alpha) S_{i, 1}^{S}+O_{1}^{S}
$$$$
\text { ; } t=1
$$

$\sum_{i=1}^{I}(1+\alpha) B_{i, t}^{S}+Q_{t}^{S}-\left(1+r l_{t}^{S}\right) Q_{t-1}^{S}+L_{t}=C_{t}+\sum_{i=1}^{I}(1-\alpha) S_{i, t}^{S}+O_{1}^{S}-\left(1+r b_{t}^{S}\right) O_{t-1}^{S}$ ; $t=2 \leq t \leq T-1$

where $Q_{t}^{S}$ are the amount of cash lent at time $t$ scenarios $s,{ }^{L_{t}}$ are the liability at time $t, C_{t}$ are the contribution at time $t, O_{1}^{S}$ are the amount of cash borrowed at time $t$ scenarios $s, r l_{t}^{S}$ are the lending rate at time $t$ scenarios $s$, and $r b_{t}^{S}$ are the borrowing rate at time $t$ scenarios $s$. This constraint tells us that the amount of new assets bought plus assets lent and all the liabilities is equal to contribution received from the members, plus cash from selling assets at time $\mathrm{t}$ and amount of cash borrowed. We assume the cost of selling $(1+\alpha)$ and buying assets $(1-\alpha)$ is $2 \%$ respectively. We also assume lending and borrowing rate is equivalent to MMI's return at time $t$, and scenario s plus 0.005 and minus 0.005 respectively. It can be written as:

$$
r l_{t}^{S} M M I_{t}^{S}+0.005 ; r b_{t}^{S}=M M I_{t}^{S}-0.005
$$

\subsubsection{Asset Value}

$$
\boldsymbol{I}_{t}=\sum_{i=1}^{t} \boldsymbol{I}_{i, t}
$$

This equation represents the total of assets held at time $t$.

\subsubsection{Portfolio constraints}

In order to ensure the fund manages the assets in a sustainable manner, the EPF enforces a bounding constraint of asset allocation in certain asset classes. Thus, the model in this study must be subject to an upper and lower bound limit of holding assets in various asset classes. In the case of Malaysia's EPF, according to The EPF act 1991, there is a lower bound and an upper bound of asset allocations in specific asset classes as stated in Table 1

Table 1: Upper and lower bound for each asset class

\begin{tabular}{|l|l|l|}
\hline Asset class & $\begin{array}{l}\text { Lower } \\
\text { bound } \\
(\%)\end{array}$ & $\begin{array}{l}\text { Upper } \\
\text { bound } \\
(\%)\end{array}$ \\
\hline $\begin{array}{l}\text { Money market instrument } \\
\text { MMI) }\end{array}$ & 5 & 25 \\
\hline Bond and loan & 15 & 35 \\
\hline Equity & 5 & 25 \\
\hline $\begin{array}{l}\text { Malaysian yevernment } \\
\text { Securities with 10 year } \\
\text { MGS10) }\end{array}$ & 15 & 45 \\
\hline Property & 0.1 & 5 \\
\hline
\end{tabular}

Source: [6]

The bound constraints for LP model is shown in the equation (10):

$$
l_{i} \sum_{i=1}^{I} H_{i, t} \leq x_{i, t} \leq u_{i} \sum_{i=1}^{I} H_{i, t}
$$

\section{MODELLING UNCERTAINTIES}

As suggested by [4] and [13], the efficiency of stochastic modelling is relied primarily on the quality and reliability of the scenarios generated to represent unknown factors. Stochastic ALM programming for this model is dealt with two uncertain factors; future asset price and future claims of liabilities. As mentioned previously, the EPF responsible to manage saving for retirement and other pre-retirement withdrawal benefit such as education, buying property, health and performing pilgrimage. Thus, in modelling liabilities factors, both the retirement withdrawal and preretirement benefit must be considered in this model. We develop five uncertain factor for this model - asset return, population model, salary model, pre-withdrawal claims model, final retirement claims model.

\subsection{Generation of asset return}




\section{THE SUSTAINABILITY OF MALAYSIA'S DEFINED CONTRIBUTION PENSION SYSTEM: IMPLEMENTATION OF DETERMINISTIC LINEAR PROGRAMMING}

Previous literatures have discussed scenario generation for stochastic programming such as [8], [5]. In this study we employ a random sampling model based on historical data. [8] used random sampling method to solve an asset liability management model for Dutch pension fund where vector autoregressive time series model (VAR) was used to estimate asset returns. In his study, Kouwenberg used VAR with lag zero as to minimize spurious in projecting future scenarios. In addition to VAR model, the simplest way to generate scenario from random sampling is to employ bootstrapping model. However, the drawback of this model is that future scenarios are only generated from historical data that available in the sample [11].

In this study we simulate asset returns scenarios based on vector autoregressive model (VAR) as suggested by [8]

$$
\begin{aligned}
R_{t} & =\mu+\Omega\left(R_{t-1}-\mu\right)+\varepsilon_{t} ; \\
(10) & t=1 \ldots . T \varepsilon_{t} \sim N(0, \Sigma) \\
R_{t}=\ln \left(1+R_{i t}\right) ; & i=1 \ldots, I, t=1, \ldots, T
\end{aligned}
$$

where $R_{i t}$ represents the return of asset $i$ at time $t$. As suggested by [6], we transformed historical return for the asset to $\ln \left(1+R_{i t}\right)$ as to avoid heteroscedasticity problem. $\mu$ represents vector of coefficient, $\Omega$ is a $\left\{\begin{array}{lll}k & \mathrm{x} & \mathrm{k}\end{array}\right\}$ autoregressive coefficient matrix, $\varepsilon_{t}$ is the vector of the error term and $\sum$ is a $\{\mathrm{k} \mathrm{x} \mathrm{k}\}$ covariance matrix.

Scenario of future returns projections in this study are modelled based on an unrestricted VAR without lagged variable. Table 2 displays the VAR estimation of $\mu$ and model equation with lag zero. Random sampling are constructed by sampling from the error distribution on the VAR model and the values then are used to project future return for each asset by recursively solve the equation in Table 2 in order to generate thousands of scenarios. In our case, we generate 200scenarios and probability to generate each scenario is equivalent 0.005 or $1 / 200$. For the purpose of deterministic model, we take the average value of the scenarios generated

Table 2: Coefficient of the VAR model for asset return for the EPF

\begin{tabular}{cc}
\hline $\ln \left(1+\right.$ klci $\left._{t}\right)$ & $=0.051026+\varepsilon_{t}$ \\
\hline $\ln \left(1+M G S 1_{t}\right)$ & $=0.039684+\varepsilon_{t}$ \\
$\ln \left(1+M G S 1_{t}\right)$ & $=0.049273+\varepsilon_{t}$ \\
$\ln \left(1+M_{\text {MI }}\right)$ & $=0.042986+\varepsilon_{t}$ \\
$\ln \left(1+\operatorname{PROP}_{t}\right)$ & $=0.060788+\varepsilon_{t}$
\end{tabular}

\subsection{Simulating future cash flows}

Pension fund cash flows consist of cash inflow and cash outflows. Pension fund cash flows have been studied extensively, see for example [16] and [9]. For the case of the $\mathrm{EPF}$, cash inflows are derived from returns from investment and contributions received from both the employers and employees. While, cash outflows refer to payment for preretirement withdrawal, payment to retirees (lump sum and annuity) and payment due to death.

To generate a scenario for unknown future liabilities and payment benefits, a twostep approach is considered namely, (i) estimating the future status of current participants such as active and retired and (ii) forecasting future salary by each participant [8]. To do this, Kouwernberg used Markov model differentiates participant status based on retired and working status in the future. Other researchers who used Markov Model are [9], [6] and [14].

In this study, we construct a population model based on an open population model which allows the new members (entrant) to be insured by the EPF. In this model, there are five states that represent the EPF members- new entrant, active members, Inactive members, retired and death. We consider death and retirement as an absorbing state where once members are classified as deceased and/or retired group they cannot move into another group. The transition from one state to another is measured by the probabilities of transition from state $i$ to state $j$ at time $t$. Transition matrixes $\mathrm{P}=[\mathrm{P} i j]$, is defined as a matrix of probabilities showing the likelihood of one state unchanged or moving to any of other state as shown in (12).

$$
P_{i j}=\frac{n_{i j}}{\sum_{j} n_{i j}}
$$

We denote $P_{i j}$ as a probability of member in certain age group being in state $j$ in the period $t$ given that they were in a state $i$ in the period $t-1$.

Once population model is generated, we then calculate a benefit paid to the members which consists of payment for pre-withdrawal payment, retirement payment and death payment. Based on historical claims, we assume that prewithdrawal claims are $13 \%$ of total contribution every year. Meanwhile, we calculate lump sum payment and death payment based on member statuses that have been generated from Markov model.

For deriving future benefit and contribution, we need to estimates the employee's salary. There is a salary increment due to merit(seniority), increase in labour's productivity and due to inflation [15] ; [16]. We can generate the salary function $(s x)$ for a group of participant at age group $x$ as follows:

$$
s_{x}=s_{y} \frac{(S S)_{x}}{(S S)_{y}}[(1+I)(1+P)]^{x-y}
$$

wherey represent the entry age of the members, $x$ are the age of the members ( $x>y),(S S)$ are the merit

salary scale at age $x, s_{y}$ are the entry age Ringgit Malaysia (RM) salary, $I$ is the inflation rate (we assume $3 \%$ ), and $P$ is the productivity rate (we assume $1.5 \%$ ).

\section{COMPUTATIONAL RESULTS}

The model is solved for the investment horizon of 45 years with 200 interest rate scenarios and the liability stream is generated using open pension scheme. We utilise Malaysia life table data, such as mortality rate and survival ratio, to project future behaviour of the EPF member. For uncertain factors, we generate the model using MATLAB 2016 and the sample generated from this analysis is then used as an input for our ALM model. We run the LP and

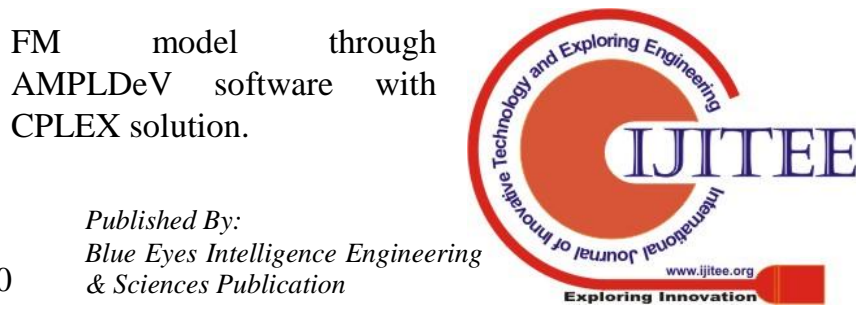


First, we present population model for the EPF. The model consists of future projection of the active member, unemployed, dead member before retirement age and future retirees. The model is generated based on Markov chain model. Table 3present the population model for the 45 years where 2015 is the first year of the projection. In Table 1, we found that the number of inactive groups is decreasing with the increase of age. The reason for this trend is believed contributed by the employment establishment where at the beginning of the career, most workers are trying to find the best job and meanwhile after the age 35 , the workers may satisfy with their current job and reduce the tendency to quit and finding a new job.

The simulated population model is based on the information which is obtained from the EPF annual report and Malaysia life table data to represent mortality rate and survival ratio. The model is represented by four states or status of the members- Active members (A), inactive members (U), Retired (R) and Dead members (D). Retired members consist of the member with age above $56(\mathrm{R} \geq 56$ years old). Detail resources of the population data is reported in Author's thesis

Table 3: Population model of the EPF for the selected yea

\begin{tabular}{|c|c|c|c|c|c|c|c|c|c|c|c|c|}
\hline \multirow{2}{*}{$\begin{array}{l}\text { Year } \\
\text { Age } \\
\text { group }\end{array}$} & \multicolumn{4}{|c|}{2016} & \multicolumn{4}{|c|}{2040} & \multicolumn{4}{|c|}{5059} \\
\hline & $\mathrm{A}$ & $\mathrm{U}$ & $\mathrm{R}$ & $\mathrm{D}$ & A & $\mathrm{U}$ & $\mathrm{R}$ & $\mathrm{D}$ & A & $\mathrm{U}$ & $\mathrm{R}$ & D \\
\hline $20-25$ & 1884705 & 104355 & & 27671.06 & 11268772 & 648745.9 & & 165915.4 & 46483033 & 2676039 & & 684391.4 \\
\hline 26-30 & 1021322 & 74457.35 & & 18497.02 & 61046.34 & 4863.739 & & 1111.467 & 6598.508 & 525.7223 & & 120.1386 \\
\hline $31-35$ & 908437.5 & 57267.66 & & 14737.35 & 593387.9 & 39725.37 & & 9665.331 & 424718.9 & 28433.53 & & 6917.985 \\
\hline $36-40$ & 589946.4 & 43008.82 & & 10684.44 & 35262.21 & 2809.443 & & 642.0168 & 3811.498 & 303.6731 & & 69.39569 \\
\hline $41-45$ & 611414.2 & 38543.39 & & 9918.815 & 399373.4 & 26736.74 & & 6505.148 & 285852.6 & 19136.89 & & 4656.077 \\
\hline $46-50$ & 414166 & 30193.91 & & 7500.903 & 24755.48 & 1972.341 & & 450.7215 & 2675.824 & 213.1907 & & 48.71855 \\
\hline 51-55 & 387071.4 & 24400.88 & & 6279.36 & 252833.6 & 16926.38 & & 4118.251 & 180966.3 & 12115.1 & & 2947.649 \\
\hline $56-60$ & & & 225347.9 & 35734.7 & & & 178779.2 & 29456.75 & & & 128434.8 & 21175.21 \\
\hline 61-65 & & & 101109.3 & 15499.07 & & & 95667.91 & 15753.65 & & & 68947.54 & 11367.15 \\
\hline 66-70 & & & 39690.35 & 5716.278 & & & 51045.4 & 8396.544 & & & 37007.87 & 6101.044 \\
\hline 71-75 & & & 13243.96 & 1771.29 & & & 27092.25 & 4447.62 & & & 19858.94 & 3273.588 \\
\hline $76-80$ & & & 3196.671 & 329.6427 & & & 14245.78 & 2330.541 & & & 10651.43 & 1755.486 \\
\hline Total & 5817063 & 372227 & 382588.2 & 154339.9 & 12635431 & 741779.9 & 366830.6 & 248793.4 & 47387657 & 2736767 & 264900.6 & 742823.8 \\
\hline
\end{tabular}

From the optimization point of view, we derive an optimal investment strategy by comparing two ALM models - the deterministic LP strategy with a FM strategy. Five major asset classes were considered and the proportion of the wealth held in each asset is known at time $t_{0}\left(t_{0}=2014\right)$ which were obtained from the EPF annual report. The objective for this model is to allocate the wealth in the asset that maximise the wealth at the planning horizon. Initially we solved the ALM model with different dividend payment$2.5 \%, 4 \%, 5 \%$ and $6 \%$.

\subsection{Linear Programming Strategy}

Based on LP strategy, it appears that the expected terminal wealth of the pension fund decreases when the EPF distributes higher dividend to its members. In figure 1, the expected terminal wealth is plotted against various dividends growth. The solution for this model depicts an increase in dividend distributed to the member drives the reduction in expected terminal wealth. Even higher interest rate rise member's pension saving during accumulation period, it also reduces the available wealth that can be invested in the financial market for the next period, thus affect the expected terminal wealth. Therefore, the decision of distribution policy is essential for the EPF to ensure the financial soundness and funding stability in the future. Table 4 indicates the summary of the expected wealth value that has been generated from LP strategy

Figure 1: Growth Dividend against expected
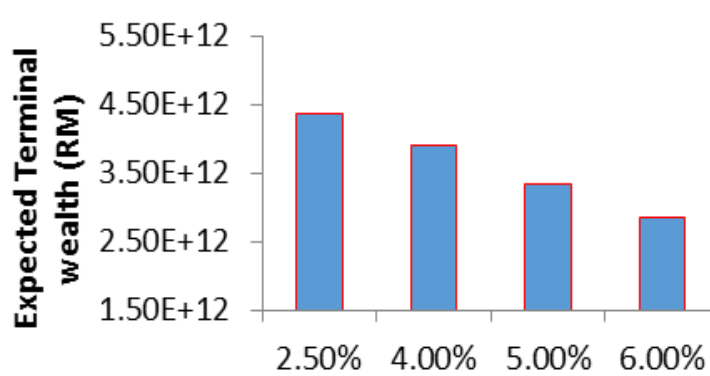

Growth Dividend (\%)

Table 4: Summary of LP Resultsterminal wealth for LP strategy

\begin{tabular}{|l|l|}
\hline Growth Dividend & $\begin{array}{l}\text { E } \\
\text { Wealth) }\end{array}$ \\
\hline $2.50 \%$ & $4.36 \mathrm{E}+12$ \\
\hline $4.00 \%$ & $3.90 \mathrm{E}+12$ \\
\hline $5.00 \%$ & $3.34 \mathrm{E}+12$ \\
\hline $6.00 \%$ & $2.84 \mathrm{E}+12$ \\
\hline
\end{tabular}




\section{THE SUSTAINABILITY OF MALAYSIA'S DEFINED CONTRIBUTION PENSION SYSTEM: IMPLEMENTATION OF DETERMINISTIC LINEAR PROGRAMMING}

We then compare the expected wealth generated from deterministic LP and the FM decision strategy. The FM stragey suggests that the proportion of the asset allocation is fixed at the beginning of the planning horizon and will be held until the end of the horizon. In this study, we determined the allocation of the asset as follows:

Table 5: Upper and lower bound for each asset class

\begin{tabular}{|l|c|}
\hline Asset class & Fixed mix (\%) \\
\hline Money market instrument (MMI) & 15 \\
\hline $\begin{array}{l}\text { Malaysian Government Securities } \\
\text { with 10 year maturity (MGS1) }\end{array}$ & 25 \\
\hline Equity & 35 \\
\hline $\begin{array}{l}\text { Malaysian Government Securities } \\
\text { with 10 year maturity (MGS10) }\end{array}$ & 25 \\
\hline Property & 5 \\
\hline
\end{tabular}

Figure 2 and Table 6 present the graph of expected terminal wealth against various dividend growths and the summary of the expected wealth value of FM respectively

Figure 2: Growth Dividend against

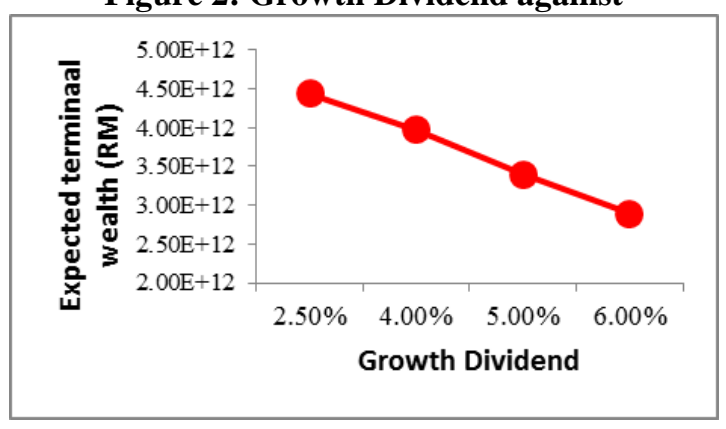

Table 6: Summary of FM Results expected terminal wealth for FM

\begin{tabular}{|c|c|}
\hline Growth Dividend & $\begin{array}{c}\text { E(Teminal } \\
\text { Wealth) }\end{array}$ \\
\hline $2.50 \%$ & $4.44 \mathrm{E}+12$ \\
\hline $4.00 \%$ & $3.97 \mathrm{E}+12$ \\
\hline $5.00 \%$ & $3.40 \mathrm{E}+12$ \\
\hline $6.00 \%$ & $2.90 \mathrm{E}+12$ \\
\hline
\end{tabular}

\section{CONCLUSION}

This study contributes to the ALM literature by introducing the pension model that is modelled specifically for the Malaysia case which has individual specific features from policy and regulation practices. Investment strategy and asset allocation are an important issue for the EPF to provide higher return for its members thus affect final benefit adequacy [7]. Thus, in this article we have introduced deterministic LP and FM model to solve optimal asset allocation problem for the EPF.
In the empirical application of this article, we generated two random factors that related to the ALM model. First is asset returns where we generate the value based on VAR model. While the second random factors used in this model is a liability and cash flow model. We used Markov chain model to generate the cash flow model and aided by population and salary projection model. The results of this study show that the FM generated higher expected terminal value than LP. Thus, we conclude that FM based optimization strategy is superior to the LP. The practical case that we obtained from the both model shows that distributing higher dividend to members leads to decreasing expected terminal wealth in the long run. Clearly, paying higher dividend will reduce available funds to be reinvested in the future during planning horizon. This finding is consistent with the finding of [6] that mentions inverse relationship between expected terminal wealth and dividend growth. Hence, the funds must consider optimal dividend policy as to derive a sound pension fund. Moreover, allocating more wealth to the relatively high risk asset generate high expected terminal wealth.

In addition to identifying optimal investment strategy with the presence of uncertainties, this study contributes to the Malaysian pension system by providing an insightful overview of the future population model which is considering the status of the EPF members in terms of number of active members who still pay contribution to the system, member who is leaving and new joining (re-joining) the system as well as the number of die members before reaching retirement age. This population model is an essence factors for the EPF in projecting their pension soundness since the model is associated with the future benefit payment that EPF is going to be made and projected future contributions that are going to be received.

\section{REFERENCES}

1. Asher, M. G. (2000). Pension reform, capital markets amd corporate governance in Malaysia. Journal of Financial Regulation and Compliance, 9(1), 30-37.

2. Bielecki, M., Goraus, k., Hagemejar, J., \& Tyrowicz, J. (2015). Decreasing fertility vs increasing longevity:rasing the retirement age in the context of ageing processes. Economic Modelling, xxx, 1-19.

3. Di Domenica, N., Lucas, C., Mitra, G., \& Valente, P. (2009). Scenario generation for stochastic programming and simulation: a modelling perspective. IMA Journal of Management Mathematics, 20(1), 1-38. doi: 10.1093/imaman/dpm027

4. Dupačová, J., \& Polívka, J. (2009). Asset-liability management for Czech pension funds using stochastic programming. Annals of Operations Research, 165(1), 528.

5. Hoyland, K., \& Wallace, S. W. (2001). Generating Scenario Trees for Multistage Decision Problems. Management Science, 47(2), 295-307.

6. Hussin, S. A. S. (2012). Employees Provident Fund (EPF) Malaysia: generic models for asset and liability management under uncertainty. (PhD), Brunel University.

7. Ja'afar, R., \& Daly, K. J. (2016). Reviewing the financial soundness of the Malaysia's 
Employees Provident Fund. Paper presented at the nternational Conference on Economics, Management and Corporate Social Responsibility (EMCSR'16), Kuala Lumpur, Malaysia.

8. Kouwenberg, R. (2001). Scenario generation and stochastic programming models for asset liability management. European Journal of Operational Research, 134(2), 279-292. doi: http://dx.doi.org/10.1016/S0377-2217(00)00261-7

9. Mettler, U. (2005). Projecting pension fund cash flows: Technical Report 1, National Centre of Competence in Research Financial Valuation and Risk Management, Zurich.

10. Mitra, G., \& Medova, E. (2010). Asset and liability management/liability-driven investment for pension funds. Journal of Asset Management, 11(2), 71-72. doi: 10.1057/jam.2010.14

11. Mitra, S. (2006). A white paper on scenario generation for stochastic programming. In O. S. W. p. Series (Ed.), (Vol. OPT004). UK.

12. Mohd, S., Azman, A., Sulaiman, J., \& Baba, I. (2010). Financial security protection in malaysia, Singapore and Philippines: A perspective of two generations. The Hong Kong Journal of Social Work, 44(2), 89-104.

13. Pflug, G., \& Świętanowski, A. (1999). Dynamic asset allocation under uncertainty for pension fund management. Control and Cybernetics, 28, 755-777.

14. Real, D. (2014). Liability Driven Investment (LDI) Strategies for Swiss Pension Funds. (PhD), University of St. Gallen, University of St. Gallen.

15. Schwaiger, K., Lucas, C., \& Mitra, G. (2010). Alternative decision models for liability-driven investment. Journal of Asset Management, 11(2), 178193. doi: $10.1057 /$ jam.2010.12

16. Winklevoss, H. E. (1982). Plasm: Pension Liability and Asset Simulation Model. The Journal of Finance, 37(2), 585-594. doi: 10.1111/j.1540-6261.1982.tb03580.x

\section{AUTHOR PROFILE}

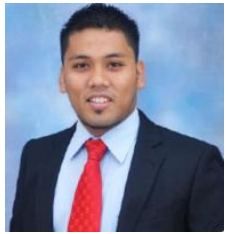

RoslanJa'afar is a lecturer at Graduate School of Business, UniversitiKebangsaan Malaysia (UKM-GSB). He received his first degree in Bachelor of Economics from UniversitiKebangsaan Malaysia, his master in Business Administration from Universiti Putra Malaysia and his Ph.D from Western Sydney University. His major research interests include social security, portfolio allocation strategy, financial market and economics.

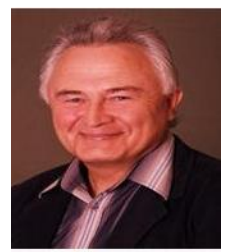

Professor Kevin Daly joined the University of Western Sydney (Macarthur) as an Associate Lecturer in 1993; prior appointments included Senior Tutor in Economics at the University of Adelaide, Lecturer in Business Studies at the University of Brighton (UK) and Economics and Fiance Tutor at Sussex University. Before joining academia Kevin worked at various positions in Merchant Banking in the City of London. Kevin holds a BA (Hons) Economics, and MA (Economics Analysis and Policy) University of Sussex and a PhD University of Western Sydney (Macarthur). Kevin's research passion revolves around applied finance and open economy macroeconomics; researching the effects of financial volatility on real economic activity. 